\title{
Where are the feminine boys? Interrogating the positions of feminised masculinities in research on gender and childhood
}

Carrie Paechter

Nottingham Centre for Children, Young People and Families

School of Social Sciences

Nottingham Trent University

Chaucer Building

Goldsmith Street

Nottingham NG1 5LT

carrie.paechter@ntu.ac.uk

+4411584882412

Twitter:@CarriePaechter

http://orcid.org/0000-0003-3050-5571

\section{Abstract}

In this paper I examine the postion of feminine boys in the literature on gender and childhood. I argue that there has been little systematic research carried out on feminine boys, and that this is the case for several reasons. I start with discussing how researchers tend to focus on dominant narratives, with the result that alternative positions are either ignored or treated as straightforwardly subordinate. Following that, I consider some of the problems associated with how we define femininity in boys, and difficulties related to naming a boy as feminine. I then call into question the assumption that feminine boys are always subordinate in schools and related settings, and discuss spaces of resistance. Finally, I suggest ways in which research could move forward in this area. 


\section{Keywords:}

Boys; masculinities; femininities; gender; childhood; education; naming; subordination; resistance

\section{Introduction}

Feminine boys occupy peripheral spaces in the literature on gender and childhood. Apart from a very few accounts focusing directly on these boys and their experiences (Martino and Pallotta-Chiarolli, 2003; Renold, 2001, 2004; Walker, 1988) they tend to appear as asides to longer and more fully developed discussions of dominant masculinities. Exceptions to the main narrative of how hegemonic masculinities are constructed in particular sites, these boys flit tantalisingly through accounts of masculinity and education, often seeming just out of reach or in the margins. This, of course, reflects their physical and spatial positions within schools, particularly with respect to the informal sites in which dominant masculinities can be best observed, such as playgrounds (Renold, 2004; Thorne, 1993).

In this paper I am going to examine why feminine boys have not been studied systematically in masculinities research, and how we might go about rectifying this. In a context in which (at least in the West) understandings of gender and gender identities are changing rapidly, it is important that we have a stronger focus on what it means to be a feminine boy, and in particular on what this is from feminine boys' perspectives, rather than from those of their dominant peers. I will not, however, come out with a clear definition of what a 
feminine boy might be. As Pascoe (2003) notes, gender researchers have a tendency to develop typologies of masculinity and slot men and boys into them, and I have no wish to do this. While I will support my argument by referring to several empirical studies of groups of boys who might be referred to as feminine, my focus is not on any particular boys or, indeed, any specific piece of research. Rather, I want to consider how and why researchers tend to ignore or sideline boys who are considered feminine, and how we can give these boys greater priority when researching masculinities.

In this paper I am taking a broad brush approach to the issue of feminine boys. While it is of course the case that things such as social class, and ethnicity have effects on which boys are seen as feminine (Archer, 2003; Paechter, 2007), this will mainly happen at a local level. Furthermore, while homophobia is likely to be a factor in the stigmatisation of feminine boys, I am not going to consider sexual orientation specifically here. My aim is to consider the phenomenon of feminine boys more broadly, though I hope that further research will be able to unpack these more specific aspects of it in particular settings.

I am going to focus on four main areas. First, I will discuss what Thorne (1993) refers to as 'big man bias': the tendency for researchers to focus on dominant narratives and thereby ignore alternative positions. I then move on to discuss some of difficulties with how we define femininity in boys. Following this, I consider the problems associated with naming (Bourdieu, 1991) a boy as feminine and the possibility that this may inhibit researchers. Next, I call into question the assumption that feminine boys are always subordinate in schools, and discuss spaces of resistance. I finish with some suggestions of how research might move forward. 


\section{Big man bias and the focus on dominant boys}

A major issue in the search for feminine boys in the gender and childhood literature is the tendency of researchers to focus on dominant narratives (Thorne, 1993). There are good reasons for this: understanding the gender regime of any setting requires us to uncover the hegemonic gender forms (Paechter, 2018b) to which children are assumed to aspire. Because ideas about gender are so powerful, unpicking a local gender regime gives us insights into other related matters, such as, for example: how power/knowledge circulates in particular spaces and communities; who is enabled to mobilise power; and where resistances are possible. It allows us to examine how dominant narratives about what it is to be a boy or girl in that setting affect how different forms of behaviour are constructed, taken up, and read. Such aspirational models of gendered identities and behaviour have real effects. In any particular setting they can: constrain the sort of person one can be and still be legible to others; allow specific groups to maintain dominance; and place some individuals in socially precarious positions.

Inclusive masculinity theory (Anderson, 2013) has challenged this dominant narrative approach to masculinity by arguing that, as homophobia has declined within wider society, popularity has replaced dominance in relationships between boys and groups of boys. In this work (Anderson, 2013; Anderson and McCormack, 2018; McCormack, 2011), popularity is seen as dependent on attributes related to inclusivity, emotional intimacy and eschewing violence. However, the relational and context-dependent nature of hegemonic masculinity (Connell and Messerschmidt, 2005; Paechter, 2012) means that 
there are settings in which these attributes could also be hegemonic, particularly among the older boys and young men who have been the main focus of inclusive masculinity studies. Furthermore, the uncritical use of the term 'popular' is problematic given that children and young people have been found to use it as a synonym for 'powerful' (Currie, Kelly, \& Pomeranz, 2007; Duncan, 2004; Paechter and Clark, 2016). The findings of inclusive masculinity researchers do suggest that age may be a factor in boys' ability to take up feminine positions, possibly due to a reduction in homophobia in the later years of schooling. It remains the case, however, that homophobic bullying is frequently reported in schools, particularly the use of the word 'gay' as a term of abuse (Bradlow, Bartram, Guasp, \& Jadva, 2017; Carlile and Paechter, 2018; Rosen and Nofziger, 2018), suggesting that such inclusive forms of masculinity are by no means universal, especially among younger children.

It is important to remember that dominant masculinities are just that: aspirational (and not for all boys (Paechter, 2012)) rather than actual (Connell, 1995; Connell and Messerschmidt, 2005). They represent a sort of ideal type that everyone is supposed to aim for, rather than what is actually found in practice. In order to maintain and justify its dominance, a local hegemonic masculinity must present itself as not just the only masculinity that anyone can or should aspire to, but the only one that can really count as masculine (Paechter, 2018b). In practice, however, there are frequently groups of boys who do not actually aspire to the local hegemonic masculinity at all. Nevertheless, there is a tendency for researchers to focus on these dominant forms or to treat those who do not conform to them as inevitably subordinate (Francis and Paechter, 2015). This is because of the visibility of dominant masculinities, particularly among children, 
for whom (due to their marginalisation in wider, adult-focused gender communities (Paechter, 2007)) gender classifications are especially salient (Lloyd and Duveen, 1992). This can lead to considerable distortion in accounts of how gender identities and relations play out in school contexts. While accounts of non-hegemonic boys tend to focus on individuals or small groups, this does not reflect a reality in which very few boys wish or are able to take up hegemonically masculine identities. Thorne (1993: 98), for example, notes that 'when I mold my data into shapes provided by the literature...I have to ignore or distort the experiences of more than half the boys in Miss Bailey's classroom'. While not all of these boys could be classified as feminine, they represent a significant group whose experiences are frequently ignored by researchers (Paechter and Clark, 2016).

Connell's (1987) original formulation of the definition of hegemonic masculinity positions all other masculinities as necessarily subordinate. She also implies that such masculinities are failed attempts at hegemonic masculinity: that all boys and men would take up hegemonic masculinities if they could. I have argued elsewhere (Paechter, 2012) that this has not been found empirically to be the case; that other ways of being can be resistant or transgressive; and that we need to consider children in these positions from their own perspective, rather than from that of the dominant. The tendency of researchers to reflect the views of hegemonic groups, and treat these other masculinities (and femininities) as subordinate, has the effect of making them subordinate in the literature. Because those studying boys have tended to assume that they share a common understanding of what it is to be masculine, hegemonic constructions have dominated accounts of masculinity in schools, 
including masculinities performed by girls (Francis, 2008; Francis and Paechter, 2015; Paechter, 2006).

This sidelining of non-hegemonic boys in the literature on masculinities and schooling is compounded by spatial considerations, which mean that these boys are frequently overlooked by researchers focusing on relatively informal contexts such as school playgrounds. Feminine boys in particular tend not to be 'where the action is' (Goffman, 1967), so they may simply not be seen by observers. Goffman describes 'situations of action' that are 'far more the scene of male activity than of female' (156). Indeed, in the settings he invokes, they could be characterised as redolent of the local hegemonic masculinities. In these situations, contests between males take place which involve risk to life, limb or reputation. He considers these to be 'character contests' (181), but they could also be regarded as occasions for the demonstration, contestation and reinforcement of local hegemonic masculinities. Goffman implies that such contests (in different forms) involve most or all men and boys, though to a greater or lesser extent depending on an individual's appetite for 'action'. However, he nevertheless acknowledges that 'character' can also be established by a conscious refusal to participate, though this carries significant risk of losing face, and is frequently hard to carry off.

For boys in dominant playground cultures, such contests and provinggrounds usually involve playing football or other national sports (Karsten, 2003; Martin, 2009; Renold, 2001; Swain, 2000). Non-dominant boys are not usually involved in these. Where this is through choice, it could be argued that the boys concerned are attempting to establish an alternative, or resistant, form of masculinity that may even challenge the local hegemonic form; examples of this 
will be discussed below. Boys may also be outside the field of action through exclusion, usually due to not meeting the locally expected norms of skill or onpitch behaviour: without staff intervention, only the most adept older boys are included in informal playground games (Paechter and Clark, 2007a). The most subordinate boys frequently withdraw themselves from playground spaces altogether, in order to avoid being bullied, therefore making themselves invisible to observers who are not actively looking for them. This puts feminine boys outside the main physical and metaphorical spaces of action. Instead, they are to be found, alongside girls and younger boys, mainly on the margins of outdoor play space, or not in the playground at all, seeking sanctuary from persecution in other areas of the school (Renold, 2004; Walker, 1988). Researchers consequently have to seek them out, and only some have had the time or the awareness to do so.

\section{Problems of definition}

A major problem in discussing feminine boys is how we define them. One approach is to consider all subordinate masculinities as feminine. In some ways, this reflects what happens in wider society: for example Archer (2003) notes that South Asian boys in the UK, subordinated as an ethnic minority, are frequently seen as feminine. I will discuss this further below, but at this point it is useful to explore the implications of so doing. A key issue here is that just as hegemonic masculinities are contextually defined, so are subordinate. Indeed, the definition of what constitutes a subordinate masculinity is directly related to, and dependent on, the local hegemonic masculinity. We cannot, therefore, treat 'subordinate masculinity' as a universal descriptor any more than we can 
'hegemonic masculinity' (Connell and Messerschmidt, 2005; Paechter, 2012). Renold's (2004) 'other boys' , for example, who stay in the classroom to work or hang out in the environment corner out of the way of more dominant children, look remarkably like younger versions of Redman and Mac an Ghaill's (Redman and Mac an Ghaill, 1997) 'muscular intellectuals' who are nearer to being hegemonic in the rarefied social world of the last two years of an academically selective boys' school. Similarly, McInnes and Couch's (2004) autobiographical accounts of their own 'pride producing recognition of the processes of knowing and in the demonstration of knowledge' (439), feminised in an Australian working-class comprehensive school, reflects the dominant ethos of the older boys at Redman's English middle-class selective one (Redman and Mac an Ghaill, 1997). Indeed, the older boys described by McCormack (2011) as relating to each other in inclusive and caring ways are dominant in their own setting but similar to Renold's marginalised and much younger group.

If we avoid using subordination as a definition of femininity in boys, however, this can leave us focusing on stereotypes. This is arguably even more problematic than using universalised cultural models in relation to definitions of hegemonic masculinity. The boundaries of what is considered culturally acceptable femininity are frequently blurred: it is much easier for girls and women to move away from strong conformity to social norms than it is for boys and men (Blaise, 2005; Kane, 2006; Martino and Pallotta-Chiarolli, 2003; Paechter, 2007, 2010; Renold, 2009; Thorne, 1993). This can lead to thinking that lacks nuance and sensitivity to local variation. Nevertheless, examining how stereotypical models of femininity are used to think about boys' behaviour illuminates changing assumptions and social mores. Kane (2006), for example, 
interviewed parents of pre-school children about hypothetical gender nonconformity in their children. While her respondents were generally encouraging of stereotypically masculine activity in girls, such as athletic competitiveness and learning to use tools, they were more ambivalent about their boys. Most of the parents were positive about boys playing with toys such as dolls, toy kitchens or tea sets, arguing that this encouraged the development of domesticity, nurturing and empathy. Some activities, however, were strongly discouraged in boys, especially by fathers. These were things Kane describes as 'icons of femininity' (159):

Parents of sons reported negative responses to their sons' wearing pink or frilly clothing; wearing skirts, dresses, or tights; and playing dress up in any kind of feminine attire. Nail polish elicited concern from a number of parents, too...Dance, especially ballet, and Barbie dolls were also among the traditionally female activities often noted negatively by parents of sons (Kane, 2006: 160)

Discussing gender nonconformity in boys in relation to such stereotypically feminine items illuminates the distinction between the traditionally feminine attributes (such as nurturing) which have been incorporated into 'acceptable' masculinity, and those which have not. Similarly, Wohlwend (2011) found that a group of boys who animated Disney Princess and other dolls as female characters had their own masculinity called into question by their peers. Other boys played with dolls in the dolls' house, but always animated dolls as male. Positioning themselves as female, even in play, appeared to be a step too far. In my own study of tomboy identities (Paechter, 2010; Paechter and Clark, 2007b) ${ }^{\mathrm{i}}$ we found that children had two intersecting ways of defining and 
identifying tomboys. One way of thinking about tomboys was that they behaved like the hegemonic boys in their particular setting, for example: by actively competing in sports and getting upset if their side lost at football; wearing particular styles of clothing or footwear; or being willing and able to fight. The other involved an active repudiation of conventional femininities, again, in relation to that setting. This might include: a refusal or reluctance to wear skirts or dresses; a resistance to being clean and neat with tidy hair; a dislike of femalelabelled sedentary occupations such as drawing or colouring; or an aversion to the colour pink. Such definitions seem to be broadly in line with those used (at least by implication) by adults, though only children seem to have the idea that one can be 'a bit tomboy': masculine in some aspects of life but feminine in others. Nevertheless, they are potentially problematic because of their reliance on local definitions of masculinity and femininity and, in particular, on what boys and girls do in that specific context: someone who is perceived, or experiences herself, as a tomboy in one setting may labelled differently in another (Safir, Rosenmann, \& Kloner, 2003).

With regard to the question of who counts as a feminine boy, however, such definitional approaches are even more problematic. While girls who identified as tomboys generally agreed with other children about what sort of person a tomboy was, this is not the case at all with feminine boys. Renold (2001, 2004), for example, studied a group of boys who were labelled as 'girlie' by their male peers, because of their lack of toughness, pro-school attitudes and play preferences. The boys themselves, however, were emphatic in their rejection of femininity. Renold (2004: 260) argues that 'the more they were positioned as 'feminine', as 'failed males', or 'failed heterosexuals', the more they traduced the 
feminine', denouncing stereotypically feminine activities as emphatically as some of our tomboys embraced those associated with masculinity. Renold points out that these boys did not play with, or in the same ways as, their female peers, unlike the tomboys we studied, several of whom played football in mixed groups. Thorne (1993) also notes that, although a large proportion of boys in the class she researched did not behave as would be predicted by traditional models of masculinity, only one took part in skipping games as an equal alongside girls.

One possible strategy for researchers to work out what it means to be a feminine boy in a particular context is to look for who is bullied or treated with suspicion by other boys. This, however, puts the hegemonic group back in charge of who 'counts' as masculine, assumes that all feminine boys are subordinate, and leads to a variety of (often implied) definitions used by different studies. Thus we have (not exclusively, and in no particular order): boys who dance or act (Gard, 2003; Martino and Pallotta-Chiarolli, 2003; Walker, 1988); boys who are marginalised, bullied, or otherwise Othered (Renold, 2004); boys who play differently from the majority (Karsten, 2003); boys who have girls' friendship patterns (Thorne, 1993); boys who play with girl groups (Karsten, 2003; Thorne, 1993); boys who take academic work seriously (Francis, 2009; Jackson, 2003; Pascoe, 2003); boys who are gay (Martino and Pallotta-Chiarolli, 2003); boys who have disabilities (Martino and Pallotta-Chiarolli, 2003). This approach is not entirely satisfactory and has the additional disadvantage that it reinforces the linked binaries of masculinity:femininity and dominant:subordinate, and makes us more likely to try to fit boys into categories put forward by others rather than starting from where they are themselves (Pascoe, 2003). 


\section{Problems of naming}

Bourdieu (1985) argues that naming has performative power, and that the power to name is contested between groups. There is a symbolic struggle between groups, he suggests, for the right to confer official names on themselves and others:

In the symbolic struggle over the production of common sense, or, more precisely, for the monopoly of legitimate naming, that is to say, official - i.e., explicit and public - imposition of the legitimate vision of the social world, agents engage the symbolic capital they have acquired in previous struggles, in particular, all the power they possess over the instituted taxonomies, inscribed in minds or in objectivity, such as qualifications (Bourdieu, 1985: 231-2)

Bourdieu is here mainly referring to official hierarchies that may be recognised with titles that are 'symbolic capital, socially and even legally recognised' (733). We may, however, apply this to the ways in which hegemonic groups in schools claim the right to name themselves and others in particular ways, as discussed in the previous section. For example, dominant groups may refer to themselves as 'cool' or 'popular' and these names may be accepted by those outside as well as those within the group (even though, as several researchers have pointed out, 'popular' children may actually be disliked by most of their peers, due to the power mobilisations they use to maintain dominance (Currie, et al., 2007; Duncan, 2004; Paechter and Clark, 2016)). This power also allows them to reinforce peer hierarchies by naming subordinate children in significantly pejorative ways and have their namings taken up by others, who may feel unable 
to resist or call them out (Adams and Kavanagh, 2018). With regard to subordinate boys, such namings may include those that impugn their masculinity either directly (weed, nerd, sissy) or indirectly (fag, gay). This is part of the process by which hegemonic groups maintain their dominance through consent supported by the threat of force (Gramsci, 1971; Paechter, 2018b): such pejorative names are allowed to become part of the taken-for-granted 'normality' of a particular peer group partly because individual members of nondominant groups are never sure when such performative naming will be turned upon them. Such namings therefore become part of a taken-for-granted gender order in which masculinity is expected to be manifested in particular behavioural performances.

Butler (1997) suggests that 'discursive practices that appear to describe (pre-existing) subjects are shown to be productive' (480). Butler argues that being interpellated, or addressed, within language, is what makes social existence possible. She suggests that being named brings someone into a social location, and that this implies that naming and being named are essential aspects of being a subject. This means that, in being called an injurious name, one is not just demeaned but also at the same time given a social existence in relation to that name. Pejorative names given to feminine boys by dominant children, therefore, are not simply demeaning descriptions but function to produce these boys actually as dweebs, sissies and so on (McInnes and Couch, 2004). Thus even a pejorative and destructive name has the function of making someone intelligible as a subject. As Youdell explains:

These categorical names are central to the performative interpellation of the subject who is unintelligible, if not 
unimaginable, without these. To be called, for example, "fag" is to be simultaneously interpellated as subject and as a particular (but equivocal) type of subject. (Youdell, 2004: 481)

Youdell goes on to suggest that the hierarchical relations constituted by this process also produce dominant identities as binary partners. Naming a boy as subordinate through the use of a pejorative label also, therefore, reinforces the position of hegemonic boys by reciprocally naming them as fully masculine. As Butler (1997) points out, a speaker who utters a derogatory slur is, in doing so, 'making linguistic community with a history of speakers' (52). The use of derogatory terms by hegemonically masculine boys to Other their more feminine peers therefore reinforces their own hegemonic positions. Being named by other boys as subordinate, because it positions one as an intelligible subject, does, however, at the same time open up the possibility of resistance through the reclaiming of the subordinated identity. I will discuss this further in the next section.

Because of the symbolic power which comes with naming, researchers working in the field of gender and childhood are frequently reluctant to describe what might otherwise be seen as feminine performances as feminine when those performing them are boys (Francis and Paechter, 2015). Francis (2008) points to a double bind, arguing that, while researchers avoid labelling boys' nonmasculine behaviour as 'feminine' in order to protect these boys from further pathologisation, we still have to consider whether, as a result of this, we reinforce misogynist stereotypes. This could be considered a form of researcher squeamishness, but the possible reluctance to 'tell things as they are' comes from a foundational ethical position that one should protect one's respondents from 
harm. It is particularly problematic for those of us who would like to study feminine boys directly: just to identify specific boys as the potential subjects of such research is likely, at least in primary and lower secondary schools, to expose them to bullying and ostracism additional to that which many currently suffer. Studying feminine boys is not, in this respect, like researching masculine girls.

In consequence, researchers cannot identify feminine boys to study by asking children which boys consider themselves feminine or which boys they know who perform in this way. Boys are highly unlikely to step forward to take up such an identity, and overtly asking others to name feminine boys is likely to lead to additional subordination. Indeed, boys who would be seen by researchers as performing femininity are often particularly eager to distance themselves from the feminine. For example, as mentioned above, Renold \{, 2004 \#1897 describes a group of boys who, while questioning gender politics and asserting their right to, among other things, prefer 'soft' music and play alternative games, were 'more openly disparaging of girls, women and femininity than the way most boys dissociate themselves from the feminine' (259). She argues that, as part of claiming and demonstrating 'boy-ness'

Boys who excluded themselves from the hegemonic practices of football, fighting and cultural/aesthetic norms (e.g. music and fashion) seemed to exaggerate the expulsion, denouncement and dissociation from 'the feminine' (259).

For researchers to name boys as feminine is therefore not just to lay them open to bullying and ridicule: such naming flies in the face of their overtly claimed identities and allegiances. 
These problems for researchers in naming the actions of those identifying as boys as performances of femininity are related to questions of what it means to be named as a feminine boy compared with a tomboy girl. While 'tomboy' can be seen as a positive thing to be called, and in our study some girls were eager to identify with it, all the names for feminine boys (sissy, girly, wimp) are used pejoratively. This brings with it a much greater pressure for repudiation: although one (South Asian) boy in one of the classes in the tomboys study claimed at one point to be 'glad to be a geek', this was a rare occurrence. This reluctance to claim the 'sissy' or 'feminine' label, and its overwhelming use as a term of abuse, was underlined by the fathers in Kane's \{, $2006 \# 5364\}$ study, who felt that their own masculinity would be at risk if their young boys started playing with iconically feminine toys. They saw themselves as accountable to the wider male community for producing adequately masculine sons (West and Fenstermaker, 1995; West and Zimmerman, 1987). This may, of course, point to why it is so difficult for boys to claim anything other than unadulterated masculinity. In a context of overall male dominance, performances by boys that could be construed as feminine have to be balanced by a denunciation of the trappings of femininity. Except in conditions of overt resistance, such a performance must be undercut by a disavowal of what it might mean. For a boy to embrace femininity as an identity would be for him to fail in his accountability to other boys for normatively performing masculinity.

These complexities leave open the question of whether it is possible for a boy to be 'a bit sissy', parallel to the partially tomboy identities claimed by several girls in my own study (Paechter, 2010; Paechter and Clark, 2007b). It is certainly the case that men and boys who have sufficient hegemonically 
masculine characteristics can get away with acting in ways that in other circumstances would be considered feminine, without compromising their claims to masculinity. It is notable, for example, that much of the earlier research supporting inclusive masculinity theory took place in settings such as sports teams in which a high level of physical prowess could be taken for granted (Adams and Kavanagh, 2018; Anderson and McCormack, 2018). Francis (2008) notes the widespread acceptability of crying among professional footballers, at least in sporting contexts, and such compensatory attributes can also be effective for boys in school. Gard (2003) discusses a professional male dancer who had maintained his 'cool, tough' (110) status at school by continuing to take part in surfing and rugby while studying ballet, an activity which would otherwise significantly undermine masculinity. Renold also points to the way that hardworking, academically able boys can avoid, or even abandon, the feminised 'geek' status by successful participation in football. Both Renold and Jackson (2003) demonstrate ways in which academically successful boys can maintain a masculine image by overtly messing about in class, while McCormack (2011)suggests that 'charisma', exemplified by energetically executed tricks, jokes and banter is central to the popularity of the inclusive and mutually supportive boys he studied. Renold (2004) notes that some boys are able to behave in these and other ways that are only partially masculine, ...so long as they engaged in some hegemonic activity. For example, boys could regularly opt out of football and fighting practices if they invested in 'heterosexual' discourses and 'being a boyfriend'...Boys could also locate themselves as 'studious' and 'pro-school' if they were also 'high flyers' on the football pitch. (Renold, 2001: 254) 
However, these boys do not claim femininity: rather, they use their participation in strongly masculine performances to compensate for what could be construed as feminine performances in other areas. The question therefore remains: is it practically possible for a boy to claim partial femininity as an identity?

\section{Questioning the assumption of subordination}

The localised nature of masculinities and femininities means that what in most contexts is seen as feminine can be hegemonically masculine in others. An example of this comes from Redman and Mac an Ghaill's (1997) account of Redman's own experiences as an older student in a selective English school in 1980. In this context, the 'muscular intellectualness' characterised by being academically successful and therefore able to 'push people around intellectually' (169) emerged as a dominant masculinity that contrasted with the more conventional forms that characterised the younger parts of the school. In a different paper, Redman (2001) argues that constructing masculinities around conventional tropes of romantic love allows young men to accommodate themselves to the dominant individualistic, middle-class ethos of the final, preuniversity years of English schooling. This taking up of particular forms of classinflected, contextually driven dominant masculinities is partially reflected by Tolman et al's (2004) account of the ways in which slightly younger boys used emotional and sexual intimacy as a way of demonstrating and consolidating heterosexual masculinities. In both studies, boys experienced romantic relationships as qualitatively different from other friendships. Yang (2014) discusses boys studying beauty industry preparation courses in a Taiwanese vocational school who perform what appears to be a stereotypical femininity, 
maintaining the soft whiteness of their bodies, wearing makeup, customising their uniforms to avoid appearing fat, and constantly checking their appearance in the mirrors around the school or that they carried with them. She argues that, in this school, 'feminized bodies and sissy masculinity were popular and held a prominent position' (405).

Nevertheless, all four examples of alternative hegemonic masculinities retain some conventionally masculine elements. The masculinity described by Redman and Mac an Ghaill (1997) valorises a form of intellectual bullying that has the potential to be a non-physical equivalent of pushing others around in the playground. The romantic masculinities of Redman's (2001) young men include an intolerance of homosexuality. He also suggests that, despite a self-positioning as antisexist, 'the vocabulary of romance made available to the boys a means of positioning girls as less powerful than themselves.' Similarly, for Tolman et al's (2004) slightly younger boys, there was a strong peer expectation both of dominance and control in their heterosexual relationships and of sharing their sexual experiences with girls with their male peers. Even the highly feminised masculinities of the 'flower beauty boys' in Yang's study did not challenge overall gender hierarchies. Not only were they dominant in relation to their female peers, but they also competed constantly against each other within the terms of the local hegemonic masculinity, through participation in fashion competitions, winning medals for competitive hairdressing, and performing as models inside and beyond the school.

Furthermore, just because a specific masculinity is subordinate, this does not necessarily mean that it can be described as feminine, even in the local context, unless we simply equate subordination with femininity. Given the work 
that most subordinate boys do to distance themselves from local femininities, this does not seem to be a very sensible approach. While hegemonic groups of boys may behave as though both girls and subordinate boys were an amorphous mass over which they can be dominant, the actual behaviour of the two groups is frequently quite different. Furthermore, even hegemonic boys treat hegemonic girls and subordinate boys very differently. In my own research (Paechter, 2018b; Paechter and Clark, 2016), for example, the 'cool' boys maintained some level of (somewhat distant) friendship with 'cool' girls, but bullied subordinate children of both genders.

We also have to recognise that there is resistance to subordination on the part of feminine boys, and that this can, in some cases, be successful. Butler (1997) points out that we need to leave open the possibility that acts of hate speech do not always work, and that, even when they do, the ways in which they call their targets into being are not necessarily final and effective. She also notes that it is possible for terms used in hate speech to be reclaimed by those at whom they are targeted: examples of this would include the reclaiming of terms such as 'queer' and the boy referred to earlier who announced that he was 'glad to be a geek'. This allows for the possibility, and, indeed, is one form, of resistance. There are several examples in the literature of how boys and young men take up and use opportunities to resist pejorative naming in a resignification of the terms involved, by proudly performing identities usually associated with femininity. This does not, however, usually involve positively claiming femininity.

Youdell, (2004) for example, describes a boy who is vilified as gay as a result of his camp presentation and excellence at ballet, who enacts a moment of 
'hyperbolic masquerade' (487) in which he takes out his pink ballet shoes and performs ballet moves to a group of admiring and applauding girls. She argues that

Scott's practices...interrupt the wounded homosexual which [a previous derogatory comment] cited and inscribed as well as provisionally reinscribing gay again differently (487).

In this example, Scott explicitly and publicly takes up markers of femininity as part of a resistant performance of gay masculinity that invokes understandings of homosexuality (as associated with femininity) accepted by wider culture. Similarly, Martino and Pallotta-Chiarolli discuss a young gay man who overtly performs some aspects of femininity both to protect himself and others from homophobia and to interrogate and resist local masculinities. They explain how he:

... used clothing, performance and humour to interrogate, mock and mimic the assumptions and prescriptions - the normalising practices - of the hegemonic heterosexual masculinist Centre. In this way, he went from being an outsider who was a passive victim of harassment to being a borderdweller....In this way, he fulfilled his aim at school which was to gain recognition of gay students and gay rights, and carve out public spaces of safety and acknowledgement for himself from other students, the curriculum and the teachers (Martino and Pallotta-Chiarolli, 2003: 86).

McInnes and Couch (2004) writing about their own experiences as working-class 'sissy' boys, describe such moments as a form of masquerade, in which someone 
who is shamed demands recognition precisely for those qualities that have led to their being shamed, by flaunting them:

If I was going to be girly (in terms of my known world) I was going to be good at it. I spoke polished received English well enough to receive top marks for Speech and Reading Aloud. From age 9 I trained in ballroom dancing and became an award-winner. I flaunted the fact that I was a "reader" (437).

In all these cases, by refusing to be silenced by the shaming actions of injurious naming, these boys resist being subordinated by explicitly and publicly embracing some aspects of what is locally recognised as feminine behaviour.

\section{Conclusion}

Feminine boys elude the researcher's gaze in many and varied ways. They absent themselves from 'where the action is'; they frequently work hard at remaining unnoticed; and they actively distance themselves from girls and girliness. This is unsurprising given the subordination of many feminine boys in school and other child-dominated contexts, as well as in wider society. Although there is greater social acceptability, even encouragement, for some aspects of the feminine, especially those focused around caring and nurturing, to have a place in dominant masculinities, there are still relatively firm lines drawn between what is allowable behaviour for a man or boy, and what is not. The requirement for accountability to wider masculinities (Kane, 2006), and therefore for restrictions on what is allowable behaviour, remains strong. While occasional, and mainly older, boys, in groups or individually, overtly resist such models of masculinity, either by cultivating an inclusive ethos (McCormack, 2011) or flaunting overt 
stereotypes of femininity, such resistances remain comparatively rare and, especially among younger children, risky in most circumstances.

The net result of this is that feminine boys are comparatively both underresearched and under-named (Francis, 2008; Francis and Paechter, 2015). Where researchers do manage to find and focus on them and consider identities and peer relations from their perspective, this tends to be in the context either of a much wider study in which they are one group out of several in a particular setting, or through the use of proxy identifiers. Neither of these is entirely satisfactory, and we need to find ways in which we can approach more directly the question of what it is to be a feminine boy. I hope that by examining some of the barriers to this work I have opened up a discussion about how to overcome them, and that others will take up my challenge and help me to find some solutions.

Studying feminine boys would have several important results. First, it would bring a wider range of examples of masculinity into the research literature, reflecting the broad spectrum of ways of 'doing boy'. Second, it would illuminate how factors such as ethnicity, social class, and sexual orientation impact upon who is seen as feminine and how that femininity is in turn percieved. Demonstrating how some children and young people can resist being stigmatised while performing femininity would suggest how we could both support such resistance and intervene in child cultures to make these performances less risky. Finally, it might give us some insights into what boys and girls, particularly those who are not part of dominant groups, have in common (Paechter, 2018a). In doing this work, we have to interrogate both theory and empirical findings. This may require some nauncing of our 
understanding of feminine masculinities and how we can encourage them to become more prevelant among boys and young men, without allowing them to become hegemonic in the strict sense (Connell, 1987) of supporting patriarchal gender relations.

\section{References}

Adams, A., \& Kavanagh, E. (2018). Inclusive ideologies and passive performances: exploring masculinities and attitudes towards gay peers among boys in an elite youth football academy. Journal of Gender Studies, $27(3)$, pp. 313-322.

Anderson, E. (2013). Adolescent masculinity in an age of decreased homohysteria. THYMOS: Journal of Boyhood Studies, 7(1), pp. 79-93.

Anderson, E., \& McCormack, M. (2018). Inclusive Masculinity Theory: overview, reflection and refinement. Journal of Gender Studies, 27(5), pp. 547-561.

Archer, L. (2003). Race, Masculinity and Schooling Maidenhead, Berks: Open University Press.

Blaise, M. (2005). Playing it Straight: uncovering gender discourses in the early childhood classroom London: Routledge.

Bourdieu, P. (1985). The social space and the genesis of groups. Theory and Society, 14(6), pp. 723-744.

Bourdieu, P. (1991). Language and Symbolic Power (G. Raymond \& M. Adamson, Trans.) Cambridge, Massachusetts: Harvard University Press.

Bradlow, J., Bartram, F., Guasp, A., \& Jadva, V. (2017). School Report: the exeriences of lesbian, gay, bi and trans young people in Britain's schools in 2017 London: Stonewall and University of Cambridge.

Butler, J. (1997). Excitable Speech: a politics of the performative London: Routledge.

Carlile, A., \& Paechter, C. (2018). LGBTQI Parented Families and Schools: visibility, representation and pride New York: Routledge.

Connell, R. W. (1987). Gender and Power Cambridge: Polity Press.

Connell, R. W. (1995). Masculinities Cambridge: Polity Press.

Connell, R. W., \& Messerschmidt, J. W. (2005). Hegemonic masculinity: rethinking the concept. Gender and Society, 19(6), pp. 829-859.

Currie, D. H., Kelly, D. M., \& Pomeranz, S. (2007). 'The power to squash people': understanding girls' relational aggression. British Journal of Sociology of Education, 28(1), pp. 23-37.

Duncan, N. (2004). It's important to be nice, but it's nicer to be important: girls, popularity and sexual competition. Sex Education, 4(2), pp. 137-152.

Francis, B. (2008). Engendering debate: how to formulate a political account of the divide between genetic bodies and discursive gender? Journal of Gender Studies, 17(3), pp. 211-223. 
Francis, B. (2009). The role of The Boffin as abject other in gendered performances of school achievement. The Sociological Review, 57(4), pp. 645-669.

Francis, B., \& Paechter, C. (2015). The problem of gender categorisation: addressing dilemmas past and present in gender and education research. Gender and Education, 27(7), pp. 776-790.

Gard, M. (2003). Moving and belonging: dance, sport and sexuality. Sex Education, 3(2), pp. 105-118.

Goffman, E. (1967). Where the Action Is. In E. Goffman (Ed.), Where the Action Is: Three Essays (pp. 105-206). London: Allen Lane The Penguin Press.

Gramsci, A. (1971). Selections from the Prison Notebooks of Antonio Gramsci (Q. Hoare \& G. Nowell-Smith, Trans.) London: Lawrence and Wishart.

Jackson, C. (2003). Motives for 'laddishness' at school: fear of failure and fear of the 'feminine'. British Education Research Journal, 29(4), pp. 583-598.

Kane, E. W. (2006). "No way my boys are going to be like that!" Parents' responses to children's gender nonconformity. Gender and Society, 20(2), pp. 149-178.

Karsten, L. (2003). Children's use of public space: the gendered world of the playground. Childhood, 10(4), pp. 457-473.

Lloyd, B., \& Duveen, G. (1992). Gender Identities and Education: the impact of starting school Hemel Hempstead, Herts: Harvester Press.

Martin, B. (2009). "Boys are from planet football? Girls are from planet pink?": Gender dualism and beyond in the construction of young children's gender identities in the early years of schooling (Goldsmiths, University of London, London.

Martino, W., \& Pallotta-Chiarolli, M. (2003). So What's a Boy? Addressing issues of masculinity and schooling Maidenhead: Open University Press.

McCormack, M. (2011). Hierarchy without hegemony: locating boys in an inclusive school setting. Sociological Perspectives, 54(1), pp. 83-101.

McInnes, D., \& Couch, M. (2004). Quiet please! There's a lady on the stage -boys, gender and sexual nonconformity and class. Discourse, 25(4), pp. 431-443.

Paechter, C. (2006). Masculine femininities/feminine masculinities; power, identities and gender. Gender and Education, 18(3), pp. 253-263.

Paechter, C. (2007). Being Boys, Being Girls: learning masculinities and femininities Maidenhead, Berks: Open University Press.

Paechter, C. (2010). Tomboys and girly-girls: embodied femininities in primary schools. Discourse, 31(2), pp. 221-235.

Paechter, C. (2012). Bodies, identities and performances: reconfiguring the language of gender and schooling'. Gender and Education, 24(2), pp. 229241.

Paechter, C. (2018a). REthinking the possibilities for hegemonic femininity: exploring a Gramscian framework. Women's Studies International Forum, May-June, pp. 121-128.

Paechter, C. (2018b). Rethinking the possibilities of hegemonic femininity: exploring a Gramscian framework. Women's Studies International Forum, 68, pp. 121-128.

Paechter, C., \& Clark, S. (2007a). Learning gender in primary school playgrounds: findings from the Tomboy Identities study. Pedagogy, Culture and Society, 15(3), pp. 317-332. 
Paechter, C., \& Clark, S. (2007b). Who are tomboys, and how do we recognise them? Women's Studies International Forum(30), pp. 342-354.

Paechter, C., \& Clark, S. (2016). Being 'nice' or being 'normal': girls resisting discourses of 'coolness'. Discourse, 37(3), pp. 457-471.

Pascoe, C. J. (2003). Multiple masculinities? Teenage boys talk about jocks and gender. The American Behavioral Scientist, 46(10), pp. 1423-1438.

Redman, P. (2001). The discipline of love: negotiation and regulation in boys' performance of romance-based heterosexual masculinity. Men and Masculinities, 4(2), pp. 186-200.

Redman, P., \& Mac an Ghaill, M. (1997). Educating Peter: the making of a history man. In D. Steinberg \& D. Epstein (Eds.), Border Patrols: policing the boundaries of heterosexuality (pp. 162-182). London: Cassell.

Renold, E. (2001). Learning the 'hard' way: boys, hegemonic masculinity and the negotiation of learner identities in the primary school. British Journal of Sociology of Education, 22(3), pp. 369-385.

Renold, E. (2004). 'Other' boys: negotiating non-hegemonic masculinities in the primary school. Gender and Education, 16(2), pp. 247-266.

Renold, E. (2009). Tomboys and 'female masculinity': (dis)embodying hegemonic masculinity, queering gender identities and relations. In W. Martino, M.

Kehler \& M. B. Weaver-Hightower (Eds.), The Problem with Boys' Education: beyond the backlash (pp. 224-241). London: Routledge.

Rosen, N. L., \& Nofziger, S. (2018). Boys, bullying and gender roles: how hegemonic masculinity shapes bullying behaviour. Gender Issues, online first

Safir, M. P., Rosenmann, A., \& Kloner, O. (2003). Tomboyism, sexual orientation, and adult gender roles among Israeli women. Sex Roles, 48(9/10), pp. 401-410.

Swain, J. (2000). 'The money's good, the fame's good, the girls are good': the role of playground football in the construction of young boys' masculinity in a junior school. British Journal of Sociology of Education, 21(1), pp. 95-109.

Thorne, B. (1993). Gender Play: girls and boys in school Buckingham: Open University Press.

Tolman, D. L., Spencer, R., Harman, T., Rosen-Reynoso, M., \& Striepe, M. (2004). Getting close, staying cool: early adolescent boys' experiences with romantic relationships. In N. Way \& J. Y. Chu (Eds.), Adolescent Boys: exploring diverse cultures of boyhood (pp. 235-255). New York: New York University Press.

Walker, J. C. (1988). The way men act: dominant and subordinate male cultures in an inner-city school. British Journal of Sociology of Education, 9(1), pp. 3-18.

West, C., \& Fenstermaker, S. (1995). Doing difference. Gender and Society, 9(1), pp. 8-37.

West, C., \& Zimmerman, D. H. (1987). Doing Gender. Gender and Society, 1(2), pp. 125-151.

Wohlwend, K. E. (2011). 'Are you guys girls?' Boys, identity texts, and Disney princess play. Journal of Early Childhood Literacy, 12(1), pp. 3-23.

Yang, H.-C. (2014). Flower boys on campus: performing and practicing masculinity. Journal of Gender Studies, 23(4), pp. 391-408. 
Youdell, D. (2004). Wounds and reinscriptions: schools, sexualities and performative subjects. Discourse, 25(4), pp. 477-493.

\section{Biographical Note}

Professor Carrie Paechter is Director of the Nottingham Centre for Children, Young People and Families at Nottingham Trent University. Her research interests include gender, power and knowledge, how children construct and understand their identities, and online research methodologies. She is particularly interested in children and young people's embodied identities and how children are understood by themselves and other actors in different social worlds, including the school, the home and the peer group. Her most recent book, LGBTQI-parented Families and Schools: visibility, representation, and pride, is co-written with Anna Carlile and published by Routledge.

i Tomboy Identities: the construction and maintenance of active girlhood. ESRC award RES00-22-1032 